\title{
Modelagem Matemática da Análise da Dor no Procedimento de Ovariohisterectomia de Cadelas
}

\author{
Marnei Dalires Zorzella* Ana Paula Brezolin Scheila Cristina Angnes Willers \\ Mestrandas em Modelagem Matemática - UNIJUÍ - 98700-000, Ijuí - RS \\ E-mail: marnei.zorzella@unijui.edu.br
}

\author{
Daniel Curvello de Mendonça Müller José Antonio Gonzalez da Silva \\ Departamento de Ciências Exatas e Engenharias e de Estudos Agrários - UNIJUí - 98700-000, Ijuí - RS \\ E-mail: cmdaniel@terra.com.br
}

\begin{abstract}
RESUMO
A dor em animais, geralmente é acarretada devido a eventos traumáticos e implica em respostas fisiológicas, emocionais e comportamentais [2]. Por sua vez, ela desencadeia a ativação de receptores específicos e respostas neurais em consequência a estímulos nociceptivos potencialmente capazes de causar lesões teciduais. Trata-se de uma experiência subjetiva acompanhada de alterações como medo, ansiedade e até mesmo pânico. O processo de avaliação da dor em animais implica em observar sinais, tais como alteração de conduta, vocalização, alterações nos parâmetros fisiológicos, entre outros [4].

$\mathrm{Na}$ busca de diminuir o desconforto sentido pelos animais, o presente trabalho tem como objetivo verificar a eficácia e o melhor intervalo da aplicação pré-operatória do Cloridrato de Tramadol no procedimento de ovariohisterectomia de cadelas. A administração do Cloridrato de Tramadol foi à analgesia usada no procedimento cirúrgico, por se tratar de um agente opióide amplamente utilizado no tratamento da dor no período pós-operatório imediato [1].

O experimento foi desenvolvido no Laboratório de técnica cirúrgica do Hospital Veterinário da Unijuí, localizado na Rua do Comércio, 3000, Bairro Universitário - Ijuí/RS, durante o período de junho de 2012 a outubro de 2013. Os animais foram divididos em três grupos, conforme o tempo de administração do Cloridrato de Tramadol pré-cirúrgico, sendo este Grupo 1 / Basal - animais que receberam apenas a analgesia pré-operatória, Grupo 2 / 6 horas animais que receberam duas aplicações de analgésicos preemptivos, sendo a primeira, seis horas antes da analgesia pré-operatória e Grupo 3 / 24 horas - animais que receberam quatro aplicações de analgésicos, a cada seis horas, durante o período de vinte e quatro horas antes da analgesia pré-operatória.

No experimento foram utilizadas 21 cadelas sem raça definida e idades variadas, com peso médio de $10 \mathrm{~kg}$ e classificadas como pacientes saudáveis - ASA I. A dosagem recebida por cada animal foi de acordo com seu peso, partindo da recomendação técnica de $6 \mathrm{mg} \mathrm{kg}^{-1}$ animal do analgésico na medicação pré-anestésica. No entanto, conforme protocolo, também foi ministrada após seis horas ao momento próximo da cirurgia. O delineamento experimental deu-se por meio de blocos casualizados, sendo que cada bloco representa um grupo e cada grupo contendo sete repetições. A avaliação da dor foi realizada através da escala visual analógica (EVA) [3], analisando os seguintes parâmetros: pressão arterial, frequência cardíaca, frequência respiratória, temperatura, escalas de avaliação de dor, desconforto e sedação.

A partir dos dados sobre a avaliação da dor foi possível fazer a análise de variância das respectivas notas. Analisando o tempo de uso do Tramadol antes da cirurgia (TUT) e tempo de avaliação da dor após cirurgia (TAD), obteve-se os quadrados médios e, a partir deles, evidenciou-se que dentre as notas da dor, não há significância do uso do fármaco em intervalos anteriores à cirurgia, mas se mostrou efetivo em 6 horas posterior a extubação, ou seja, após o ato cirúrgico.

A seguir, o teste de médias de Scott \& Knott mostra a avaliação da dor em minutos/horas.
\end{abstract}


Tabela 1. Análise comportamental entre as médias da Dor através do Teste de Scott \& Knott, UNIJUÍ, 2014.

\begin{tabular}{ccc}
\hline $\begin{array}{c}\text { Tempo de avaliação da Dor } \\
\text { (minutos/horas) }\end{array}$ & $\begin{array}{c}\text { Média } \\
\text { Nota de dor }\end{array}$ & $\begin{array}{c}\text { Média } \\
\text { Por Grupo }\end{array}$ \\
\hline $360 / 6$ & $3.26 \mathrm{a}$ & $2.90 \mathrm{a}$ \\
$300 / 5$ & $2.90 \mathrm{a}$ & \\
$240 / 4$ & $2.53 \mathrm{a}$ & $1.14 \mathrm{~b}$ \\
$180 / 3$ & $1.61 \mathrm{~b}$ & \\
$120 / 2$ & $1.07 \mathrm{~b}$ & \\
$60 / 1$ & $0.74 \mathrm{~b}$ & \\
\hline
\end{tabular}

Através da comparação entre as médias da dor, como mostra a Tabela 1, foi possível diagnosticar que os tempos 6,5 e 4 horas pós-operatórias não diferem entre si quanto a dor, bem como os tempos 3, 2 e 1, que por sua vez também não diferem entre si. Isso indica que não houve reação adversa do animal, ou seja, não houve manifestação de dor nas três primeiras horas. Entre a terceira e quarta hora a média por grupo mostra que houve um aumento significativo no parâmetro dor, ou seja, a dor aumentou e se manteve até a sexta hora, momento este em que os animais foram novamente medicados. Cabe salientar que a dor aqui relatada, encontra-se dentro de limiares considerados baixos, recomendado pelo Colégio Brasileiro de Experimentação Animal (COBEA), sendo o índice de 3.3 o limite máximo antes da intervenção medicamentosa.

Tabela 2. Resumo da análise de variância de equação de regressão dos resultados das médias da Dor. UNIJUÍ, 2014.

\begin{tabular}{lcccc}
\hline Fonte de & Quadrado & Nota de Dor & Nota estimada & Nota observada \\
Variação & Médio & $\mathrm{y}=\mathrm{a} \pm \mathrm{bx}$ & $180 \mathrm{~min})$ & 1.74 \\
\hline Linear & $108.59^{*}$ & $\mathrm{y}=0.120+0.0090 \mathrm{x}$ & - & 1.61 \\
Quadrática & $0.063^{\text {ns }}$ & - & - \\
\hline
\end{tabular}

*Significativo em 5\% de probabilidade de erro, NS - Não significativo em 5\% de probabilidade de erro.

A análise da regressão referente à Tabela 2 mostra o comportamento da dor no período de seis horas após a extubação, indicando o modelo de equação linear como sendo o mais adequado, uma vez que este se mostra significativo em $5 \%$ de probabilidade de erro, quando observada na terceira hora (180 minutos). Substituindo o tempo (em minutos) na equação se verificou uma grande aproximação entre a nota estimada 1.74 e a nota observada 1.61.

A partir desta análise é possível afirmar que no período de observação de seis horas após extubação, à medida que se passam as horas, a ação analgésica promovida pelo Cloridrato de Tramadol no procedimento proposto, tende a diminuir, e consequentemente, a nota da avaliação da dor irá aumentar linearmente independentemente do processo sedativo preemptivo administrado anterior ao procedimento cirúrgico.

Palavras-chave: Modelagem, Ovariohisterectomia, Dor e Analgesia.

\section{Referências}

[1] ANDRADE, S. F. Manual de Terapêutica Veterinária. $3^{\text {a }}$ Ed. Roca, p.104, 2008, SP.

[2] PIMENTA, C. A. M; TEIXEIRA M. J. Avaliação da Dor. Rev. Med. v. 76, n. 1, p. 27- 35, 1997.

[3] SOUSA, F. A. E. F. Dor: o quinto sinal vital. Revista Latino-Americana de Enfermagem, Ribeirão Preto, v.10, n. 3, p. 446-7, 2002.

[4] WALL, P. D. Defining 'pain in animals'. In: SHORT, C.E., POZNAK, A. V. Animal pain. New York: Churchill Livingstone, 1992, cap. 3. p. 63-79. 